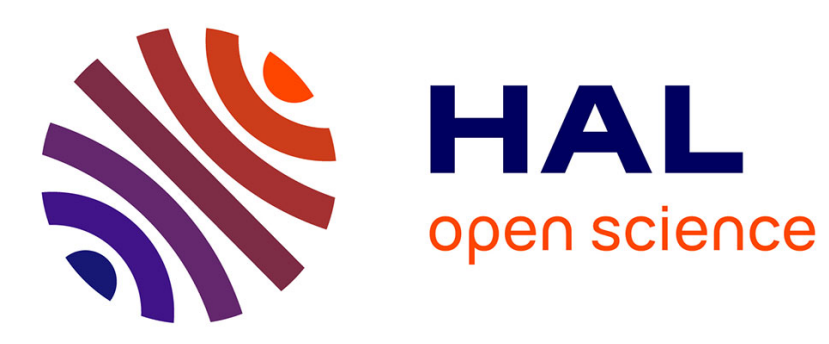

\title{
Numerical optimization of liner impedance in acoustic duct
}

K Billon, E de Bono, M Perez, E Salze, G Matten, M Ouisse, M Volery, H Lissek, J Mardjono, M Collet

\section{- To cite this version:}

K Billon, E de Bono, M Perez, E Salze, G Matten, et al.. Numerical optimization of liner impedance in acoustic duct. SMASIS, Sep 2020, Los Angeles (virtual), United States. 10.1115/SMASIS2020-2435 . hal-03236914

\section{HAL Id: hal-03236914 \\ https://hal.science/hal-03236914}

Submitted on 26 May 2021

HAL is a multi-disciplinary open access archive for the deposit and dissemination of scientific research documents, whether they are published or not. The documents may come from teaching and research institutions in France or abroad, or from public or private research centers.
L'archive ouverte pluridisciplinaire HAL, est destinée au dépôt et à la diffusion de documents scientifiques de niveau recherche, publiés ou non, émanant des établissements d'enseignement et de recherche français ou étrangers, des laboratoires publics ou privés. 


\title{
Numerical optimization of liner impedance in acoustic duct
}

\author{
K. Billon ${ }^{\mathrm{a}}$, E. De Bono ${ }^{\mathrm{a}}$, M. Perez ${ }^{\mathrm{a}}$, E. Salze ${ }^{\mathrm{b}}$, G. Matten ${ }^{\mathrm{c}}$, M. Ouisse ${ }^{\mathrm{c}}$, M. Volery ${ }^{\mathrm{d}}$, H. Lissek ${ }^{\mathrm{d}}$, \\ J. Mardjono ${ }^{\mathrm{e}}$, and M. Collet ${ }^{\mathrm{a}}$ \\ ${ }^{a}$ Univ. Lyon, École Centrale de Lyon, LTDS UMR 5513, F-69134 Ecully, France \\ ${ }^{\mathrm{b}}$ Univ. Lyon, École Centrale de Lyon, LMFA UMR 5509, F-69134 Ecully, France \\ 'Univ. Bourgogne Franche-Comté, FEMTO-ST Institute, CNRS/UFC/ENSMM/UTBM, \\ Department of Applied Mechanics, 24 rue de l'Epitaphe, F-25000 Besançon, France \\ ${ }^{\mathrm{d}}$ Signal Processing Laboratory LTS2, Ecole Polytechnique Fédérale de Lausanne, Station 11, \\ CH-1015 Lausanne, Switzerland \\ eSafran Aircraft Engines, F-75015, Paris, France
}

\begin{abstract}
The SALUTE project aims at evaluating performance of metacomposites for acoustic smart lining in grazing turbulent flow. Theoretical and numerical investigations are carried out for designing innovative specimen. A specific focus is placed in the realization of prototypes for evaluating the metacomposite liner performances in 2D and 3D liners, its process complexity and robustness. The insight gain in this project is new tools for obtaining innovative samples; the acoustical experimental tests demonstrate efficiency and robustness of such technology for controlling UHBR noise emission. This paper is focused on parametric study based on the maximization of the absorption coefficient in a duct by optimizing the impedance of a treated area.
\end{abstract}

\section{INTRODUCTION}

SALUTE (Smart Acoustic Lining for UHBR Technologies Engines) is a research project funded by the European Union's Horizon 2020 research and innovation programme Clean Sky 2 Joint Undertaking. It aims at developping innovative acoustic treatments for engine nacelles in order to reduce noise pollution of future aircrafts. The main technological objective is the development of a new generation acoustic liner, based on the Electroacoustic Absorber concept.

UHBR Technologies Engines have larger fan and shorter nacelles which present new challenges in terms of noise signature (more low-frequency components and less space for acoustic liners). In order to meet the required noise performance at engine level, next generation acoustic treatments should achieve significant noise reduction with limited surface, break the quarter-wavelength rule. Hence, the development and the optimization of an active acoustic liner prototype (2D arrangement of small electroacoustic transducers used as active membrane sound absorbers). Passive structures are good candidates to reduce high frequency contributions of noise and vibrations while active control technologies ${ }^{1}$ are suited to attenuate the low frequency components. In this context, hybrid absorbers for flow ducts have been studied and it appears that the noise reduction is directly linked to the optimal impedance in the treated area. Tester ${ }^{2}$ demonstrated that in the case of a semi-infinite duct with flow, the optimal resistance and the optimal reactance are frequency-dependent. A version, without flow, is also available. ${ }^{3}$ A hybrid impedance control architecture for an electroacoustic absorber is designed according to a target specific acoustic impedance. ${ }^{4}$ An application of this architecture has been studied with, for example, an acoustic diode. ${ }^{5}$

In this paper, a parametric study based on the maximization of the absorption coefficient has been achieved in a duct by optimizing the impedance of a treated area.

Further author information: (Send correspondence to Manuel Collet)

E-mail: manuel.collet@ec-lyon.fr 


\section{DUCT DESCRIPTION}

The geometry of the numerical duct of this study is inspired by the Phare 2 test rig for fan with $1 / 3$ reduced scale (figure 1) located at Ecole centrale de Lyon in France.

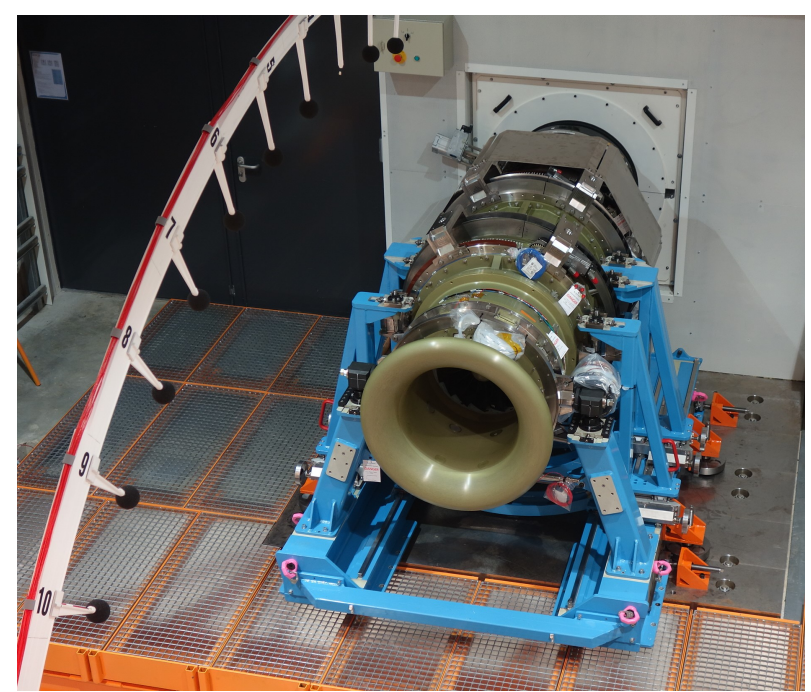

Figure 1. PHARE 2 - TEST RIG FOR FAN WITH 1/3 REDUCED SCALE.

Some assumptions are done compared to the experimental setup. The numerical duct (figure 2) is perfectly cylindrical, the acoustic perturbation is a plane wave without flow, the termination of the duct is anechoic and the treated area is a perfect ring (all impedance of the surface is considered). The cylinder is oriented along the $\mathrm{x}$ axis with 3 main parts: the upstream duct, the "sample" duct (treated ring) and the downstream duct. The upstream and downstream ducts have the same length $\left(L_{1}=L_{2}\right)$ and the same radius $\left(r_{c y l}\right)$. The treated ring (in red) has 2 different lengths equal to $d$ or $2 d$, commonly called in this paper " 1 ring" and " 2 rings" and a radius similar to the upstream and downstream ducts. The plane wave radiating surface is located at $-L_{1}$ and the anechoic termination at $d+L_{2}$. Finally, 4 microphones (pressure measurement points) are present at $-x_{1}, x_{2}, d+x_{1}$ and $d+x_{2}$. All geometrical parameters are referred in the table 1 . The cutoff frequency $\left(f_{c}\right)$ of the tube is equal to $343 \mathrm{~Hz}$.

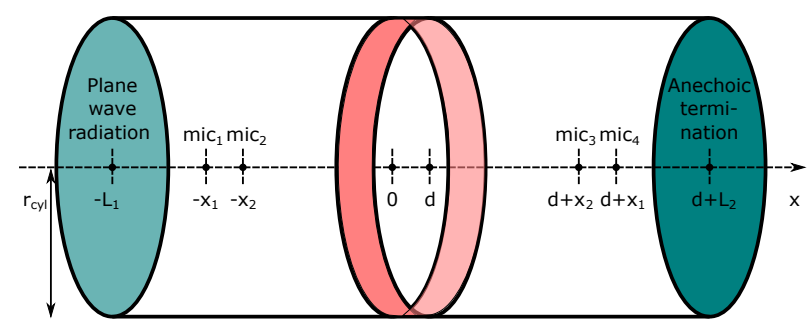

Figure 2. NUMERICAL DUCT.

\begin{tabular}{c|c|c|c|c|c}
$r_{c y l}$ & $L_{1}$ & $L_{2}$ & $d$ & $x_{1}$ & $x_{2}$ \\
\hline $0.25 \mathrm{~m}$ & $0.5 \mathrm{~m}$ & $0.5 \mathrm{~m}$ & $5.5 \mathrm{~cm}$ & $0.35 \mathrm{~m}$ & $0.3 \mathrm{~m}$ \\
Table 1. GEOMETRICAL PARAMETERS.
\end{tabular}

\section{PARAMETRIC STUDY}

The objective of this parametric study is the maximization of the absorption coefficient $(\alpha)$ in the duct presented in the previous section. An impedance expresses in frequency domain as: 


$$
Z(\omega)=a+i b,
$$

with $a$ and $b$ respectively the real and the imaginary parts of the impedance, is defined on the surface of the treated area (red ring in figure 2).

Acoustic quantities, described below, are defined following the $B \& K$ technical review. ${ }^{6}$ The transfer matrix is the link between the pressure and the velocity at $x=0$ and $x=d$, the 2 sides of the "sample" duct:

$$
\left(\begin{array}{l}
P \\
V
\end{array}\right)_{x=0}=\left(\begin{array}{ll}
T_{11} & T_{12} \\
T_{21} & T_{22}
\end{array}\right)\left(\begin{array}{l}
P \\
V
\end{array}\right)_{x=d} .
$$

The transfer matrix coefficients are obtained using the 4 microphones pressures at $-x_{1},-x 2, d+x_{1}$ and $d+x_{2}$ and then calculating the pressure and velocity: $P(x=0), V(x=0), P(x=d)$ and $V(x=d)$.

These coefficients can be used to evaluate the normal incidence pressure transmission $\left(T_{a}\right)$ and reflection $\left(R_{a}\right)$ coefficients for the case of an anechoic termination:

$$
T_{a}=\frac{2 e^{1 i * k * d}}{T_{11}+\frac{T_{12}}{\rho_{0} c_{0}}+\rho_{0} c_{0} T_{21}+T_{22}},
$$

where $\rho_{0}, c_{0}$ and $k$ are respectively the air density, the sound speed and the wave number. And

$$
R_{a}=\frac{T_{11}+\frac{T_{12}}{\rho_{0} c_{0}}-\rho_{0} c_{0} T_{21}-T_{22}}{T_{11}+\frac{T_{12}}{\rho_{0} c_{0}}+\rho_{0} c_{0} T_{21}+T_{22}} .
$$

The transmission loss (TL) is defined using the transmission coefficient:

$$
T L=10 \log _{10}\left(\frac{1}{\left|T_{a}\right|^{2}}\right),
$$

and the absorption coefficient $(\alpha)$ using both transmission and reflection coefficients:

$$
\alpha=1-\left|T_{a}\right|^{2}-\left|R_{a}\right|^{2} .
$$

Evaluated acoustic quantities $\left(T_{a}, R_{a}\right)$ has been compared with the method using the pressure and velocity in only 2 points.

The real part $(a=\operatorname{Re}(Z))$ and the imaginary part $(b=\operatorname{Im}(Z))$ of the impedance defined on the treated surface and the length of the treated duct $(d)$ are the 3 parameters of the parametric study. The length of the treated duct is equal to $d$ ( 1 ring) or $2 d$ ( 2 rings). The parameters' limits were initially defined by a rough calculation. The discretization and the limits were then adjusted. For each frequency, all combinations are tested and the couple $(a, b)$ which gives the best absorption coefficient is selected. Results are presented in the next section. 


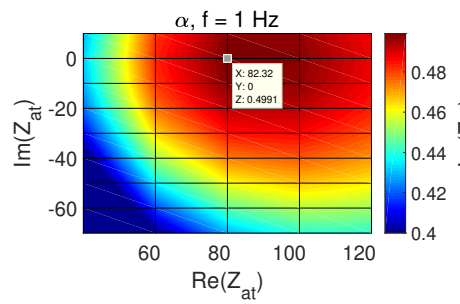

(a)

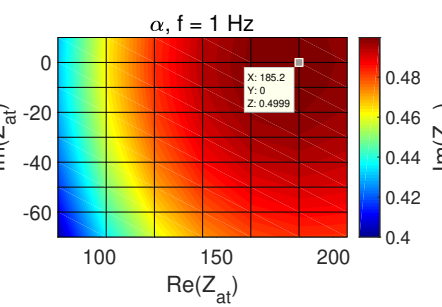

(b)

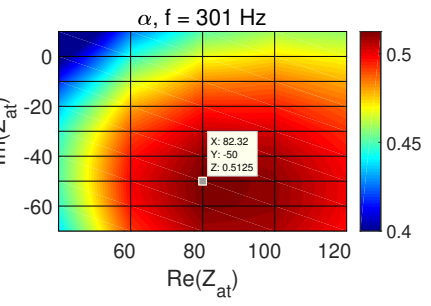

(c)

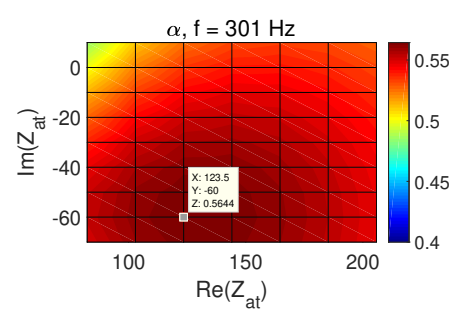

(d)

Figure 3. ABSOPTION COEFFICIENT DEPENDING ON THE REAL AND THE IMAGINARY PARTS OF THE IMPEDANCE. a) 1 TREATED RING AT 1 HZ. b) 2 TREATED RING AT 1 HZ. a) 1 TREATED RING AT 301 HZ. b) 2 TREATED RING AT $301 \mathrm{HZ}$.

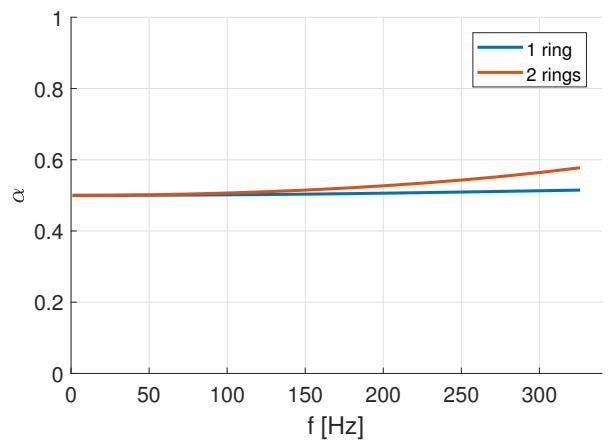

Figure 4. MAXIMIZED ABSORPTION COEFFICIENT.

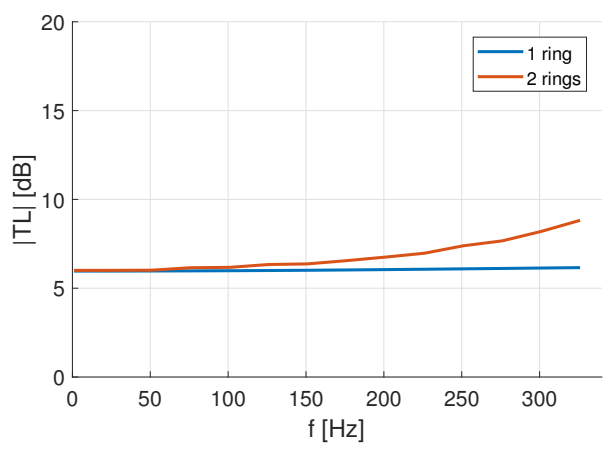

Figure 5. TRANSMISSION LOSS FOR OPTIMIZED IMPEDANCE.

\section{RESULTS}

Figures 3 present absorption coefficients depending on the real and the imaginary parts of the impedance for 1 and 2 treated rings at $1 \mathrm{~Hz}$ and $301 \mathrm{~Hz}$. The emergence of single maximums has been observed in the different cases in the frequency range. Data cursors on figure 3 indicate maximum absorption coefficients in the 4 presented cases. 
The best absorption coefficient can be plotted depending on the frequency, for the 1 and 2 treated rings configurations (figure 4). The absorption coefficient for 2 treated rings is better than 1 treated ring. In both cases, it greater than 0.5, constant for 1 treated ring. For 2 treated rings, an increase with the frequency is observed but without exceeding 0.6.

This parametric study is not focused on the transmission loss. For information, figure 5 shows the transmission loss and no discontinuity is observed.

Figures 6 and 7 show the optimized impedance $\left(Z_{a t}\right)$ for 1 and 2 treated rings. The active parts $\left(\operatorname{Re}\left(Z_{a t}\right)\right)$ of the impedance (figure 6) are still positive meaning stability. Imaginary part (figure 7 , reactive parts of the impedance are negative, decrease with the frequency and are almost similar.

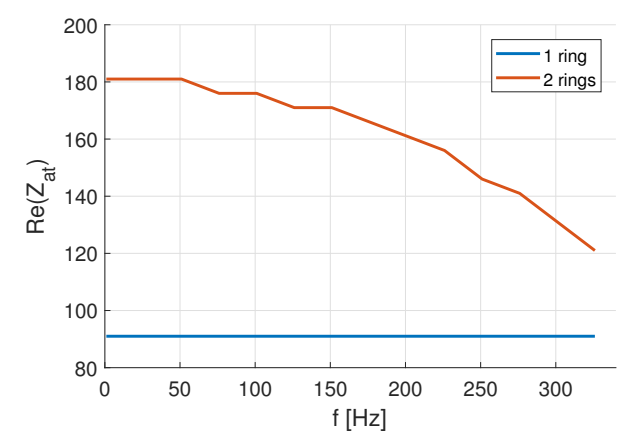

Figure 6. REAL PART OF THE OPTIMIZED IMPEDANCE.

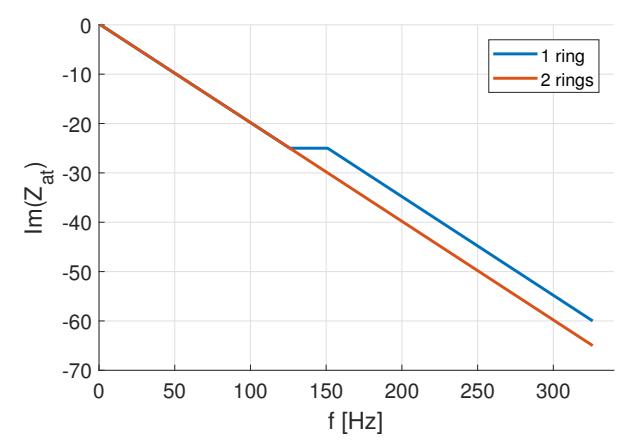

Figure 7. IMAGINARY PART OF THE OPTIMIZED IMPEDANCE.

For the 1 treated ring case, the optimal impedance, fitted from the plot, can be written as follow:

$$
Z_{a t}=\rho_{0} c_{0} / 5-0.32 \times i \omega .
$$

The value of the inertia term is negative. These data will be taken into account in the future implementation.

\section{CONCLUSION}

This article presents a parametric study based on the maximization of the absorption coefficient in a duct by optimizing the impedance of a treated area. For 1 and 2 treated rings, active parts of the impedance are still positive that means passivity. The optimized impedance will be adapt in a liner based on arrays of unit cells. Each unit cell will be composed of a transducer (a loudspeaker), 5 microphones and a control card with localized or distributed (non-localized) control strategies. 


\section{ACKNOWLEDGMENTS}

The SALUTE project has received funding from the Clean Sky 2 Joint Undertaking under the European Union's Horizon 2020 research and innovation programme under grant agreement No 821093. This publication reflects only the author's view and the JU is not responsible for any use that may be made of the information it contains.

\section{REFERENCES}

[1] M.-A. Galland, B. Mazeaud, and N. Sellen, "Hybrid passive/active absorbers for flow ducts," Applied acoustics 66(6), pp. 691-708, 2005.

[2] B. Tester, "The propagation and attenuation of sound in lined ducts containing uniform or "plug" flow," Journal of Sound and Vibration 28(2), pp. 151-203, 1973.

[3] B. Tester, "The optimization of modal sound attenuation in ducts, in the absence of mean flow," Journal of Sound and Vibration 27(4), pp. 477-513, 1973.

[4] E. Rivet, S. Karkar, and H. Lissek, "Broadband low-frequency electroacoustic absorbers through hybrid sensor-/shunt-based impedance control," IEEE Transactions on Control Systems Technology 25(1), pp. 63$72,2016$.

[5] S. Karkar, E. De Bono, M. Collet, G. Matten, M. Ouisse, and E. Rivet, "Broadband nonreciprocal acoustic propagation using programmable boundary conditions: From analytical modeling to experimental implementation," Physical Review Applied 12(5), p. 054033, 2019.

[6] J. S. Bolton, T. Yoo, and O. Olivieri, "Measurement of normal incidence transmission loss and other acoustical properties of materials placed in a standing wave tube," Brüel \& Kjær Technical Review (1), pp. 1-44, 2007. 